\title{
Recovery of Vanadium from Acid and Basic Leach Solutions of Spent Vanadium Pentoxide Catalysts
}

\author{
Hugo Calderón and Diana Endara \\ Faculty of Chemical Engineering and Agro-industry, Extractive Metallurgy Department, Escuela Politécnica Nacional, Quito EC \\ 17012759, Ecuador
}

\begin{abstract}
The vanadium pentoxide catalysts are used in the sulfuric acid manufacture, but as an inherent consequence of the process, they are deactivated or poisoned, because of that they need to be renewed. In Ecuador, the increase of environmental pollution concerns and the legislation related with the final dispose of hazardous residues is forcing to companies to process their waste products and residues. For the present investigation, catalysts samples were characterized using AAS (atomic absorption spectroscopy), XRD (X-ray diffraction), surface area (BET) and SEM-EDS (scanning electron microscopy). Results show presence of 6-5\% w/w of vanadium pentoxide $\left(\mathrm{V}_{2} \mathrm{O}_{5}\right), 10-11 \% \mathrm{w} / \mathrm{w}$ of potassium oxide $\left(\mathrm{K}_{2} \mathrm{O}\right)$ and $55-60 \% \mathrm{w} / \mathrm{w}$ of silicon oxide $\left(\mathrm{SiO}_{2}\right)$. The material presents a pore size of $3 \mathrm{~nm}$ and a specific surface area of $200 \mathrm{~m}^{2} / \mathrm{s}$. The spent catalyst was firstly pulverized in a powder mill until $200 \mu \mathrm{m}$ was attempted, then a calcination at $450{ }^{\circ} \mathrm{C}$ was made. Different leaching agents were used: nitric, sulfuric, hydrochloric acid and sodium hydroxide with variation of percentage of solids, particle size, leaching agent concentration and leaching time. Sodium carbonate was added to the solution to obtain a precipitate. A final calcination step was made at $450{ }^{\circ} \mathrm{C}$ to obtain vanadium pentoxide. The best results were obtained by using sulfuric acid at $75 \mathrm{~g} / \mathrm{L}, 20 \mathrm{w} / \mathrm{w}$ percentage solids, environmental temperature, agitation speed was maintained 750 rpm and 30 minutes leaching, the recovering vanadium rate was $94.41 \%$. In the precipitation stage $92.2 \%$ of sodium meta vanadate, for that a $\mathrm{pH} 7$ was required. Finally, precipitation was calcinated getting vanadium pentoxide at $97 \%$ purity and it costs is $\$ 104.5$ per 500 grams.
\end{abstract}

Key words: Vanadium, deactivated, poisoned, catalyst, spectroscopy, diffraction, leaching, calcinations.

\section{Introduction}

The vanadium pentoxide catalysts are used in the sulfuric acid manufacture, but as an inherent consequence of the process they are deactivated or poisoned, reason why they need to be renewed. The vanadium content is around $4-5 \% \mathrm{w} / \mathrm{w}$, this element has many industrial uses and it is categorized as dangerous and toxic for environment $[1,5]$.

In Ecuador, the increase of environmental pollution concerns and the legislation related with the final dispose of hazardous residues is forcing the companies to process their waste products and residues $[3,4]$.

Industries supplied vanadium pentoxide catalyst used in its manufacture of acid sulphuric acid for the production of detergents, oil refining, treatment of steel,

Corresponding author: Diana Endara, Ph.D. chemical engineer, research fields: recovery of nickel, vanadium and molybdenum spent catalyst unit Fluid Catalytic Cracking. soap, fertilizers and others. In the last year the industries have in stock metric tons of catalytic residues and they are forced to seek environmental managers to process them, otherwise they have to pay high fines. The actual treatment of toxic and hazardous residues consists of spent catalysts vitrification and later controlled dumping in specific areas $[1,5,6]$.

The purpose of the present work is to study the possibilities for treat the catalyst residues and to study optimum vanadium pentoxide recovery from spent vanadium pentoxide catalyst. The recovery consists in leaching, following of precipitate by converting the vanadium into vanadate and finally calcination a high temperature of the obtained vanadium pentoxide [2].

Today, over $85 \%$ of the world production of vanadium is consumed in carbon and stainless steel making alloying agents to produce ferro vanadium, in ceramic and chemical industries. Demand from uses in 
expected to grow at about 5\% annually. China, South Africa and the USA produce vanadium pentoxide from vanadium bearing magnetite ores, concentrates and slags while Japan produce vanadium pentoxide from petroleum residues, ash, and spent catalysts. Actually, vanadium pentoxide at $>97 \%$ purity costs $\$ 104.5$ per 500 grams $[5,6]$.

\section{Experiment}

\subsection{Chemical Characterization}

Catalysts samples were characterized using atomic absorption spectrophotometry in a Perkin AA300. The mineralogical composition was determined by X-ray diffraction Bruker D8 Advance. The surface area and Porosity was determined by BET. SEM images of samples were obtained by using equipment Vega-Tescan.

\subsection{Leaching Process}

\subsubsection{Pretreatment of the Catalyst}

Spent catalysts samples were firstly pulverized in a powder mill for 15 minutes in order to obtain different particle micro sizes. Later, the samples were calcined at $450{ }^{\circ} \mathrm{C}$ in a furnace for 3 hours to remove coal and sulfur waste in the form of gas, as $\mathrm{CO}_{\mathrm{x}}$ and $\mathrm{SO}_{2}$. After calcination, the samples were cooled at environmental temperature.

\subsubsection{Leaching Process}

Different leaching agents were used: nitric, sulfuric, hydrochloric acid and sodium hydroxide to extract vanadium from samples. Different factors were studied in the leaching process were pretreatment of samples, variation of percentage of solids, particle size, leaching agent concentration and leaching time. After that, the solution was filtered obtaining clarified solution and solid residue silicon oxide.

All the leaches were realized at environmental temperature with a constant mixing velocity of $750 \mathrm{rpm}$. Vanadium percent recovery is determined by dividing the mass of leached solution with the initial mass of the sample.

\subsection{Vanadium Precipitation}

Solution sodium carbonate $2 \mathrm{M}$ was added to the leaching solution to obtain a precipitate of sodium meta vanadate $\left(\mathrm{NaVO}_{3}\right)$. Later, the precipitate was calcined at $450^{\circ} \mathrm{C}$ to obtain vanadium pentoxide $\left(\mathrm{V}_{2} \mathrm{O}_{5}\right)$.

\section{Results and Discussion}

\subsection{Chemical Characterization}

Two samples of vanadium pentoxide catalyst were characterized, one called activate state and spend state. Vanadium pentoxide catalysts present the following vanadium composition observed in Table 1.

In Table 1 the vanadium content of each sample is shown. Vanadium is around 5.2 percentage inside activated catalysts, but in consequence of the catalytic process, they are deactivated or poisoned and the vanadium percentage reduce around 4 percentage for the spend catalyst. The temperature, time reaction and the raw material proprieties in the process are the main factors that cause the reduction of vanadium content.

Vanadium pentoxide catalysts present the following mineralogical composition observed in Table 2.

In Table 2 the active catalyst and the spend catalyst composition is shown. The amount of pentoxide vanadium, potassium oxide and silicon oxide is fewer than the amount of these three components on the active catalyst, this happens because of the catalyst uses. The ferric oxide appears on the spend catalyst, because the iron is part of the alloy that conforms the reactor material where the process takes place.

A comparison of the two types of catalyst is shown by the SEM images obtained in figure 1 a) section of

Table 1 Vanadium composition of vanadium pentoxide catalysts.

\begin{tabular}{lll}
\hline Sample & State & Vanadium content (\%) \\
\hline Vanadium pentoxide catalysts & Activate & 5.2 \\
Vanadium pentoxide catalysts & Spend & 4 \\
\hline
\end{tabular}


Table 2 Mineralogical composition of vanadium pentoxide catalysts.

\begin{tabular}{llll}
\hline Compound & Formula & $\%$ & $\%$ \\
(Active catalysts) & (Spend catalysts) \\
\hline Vanadium pentoxide & $\mathrm{V}_{2} \mathrm{O}_{5}$ & 8 & 6 \\
Potassium oxide & $\mathrm{K}_{2} \mathrm{O}$ & 16 & 15 \\
Silicon oxide & $\mathrm{SiO}_{2}$ & 76 & 74 \\
Ferric oxide & $\mathrm{Fe}_{2} \mathrm{O}_{3}$ & - & $<2$ \\
\hline
\end{tabular}
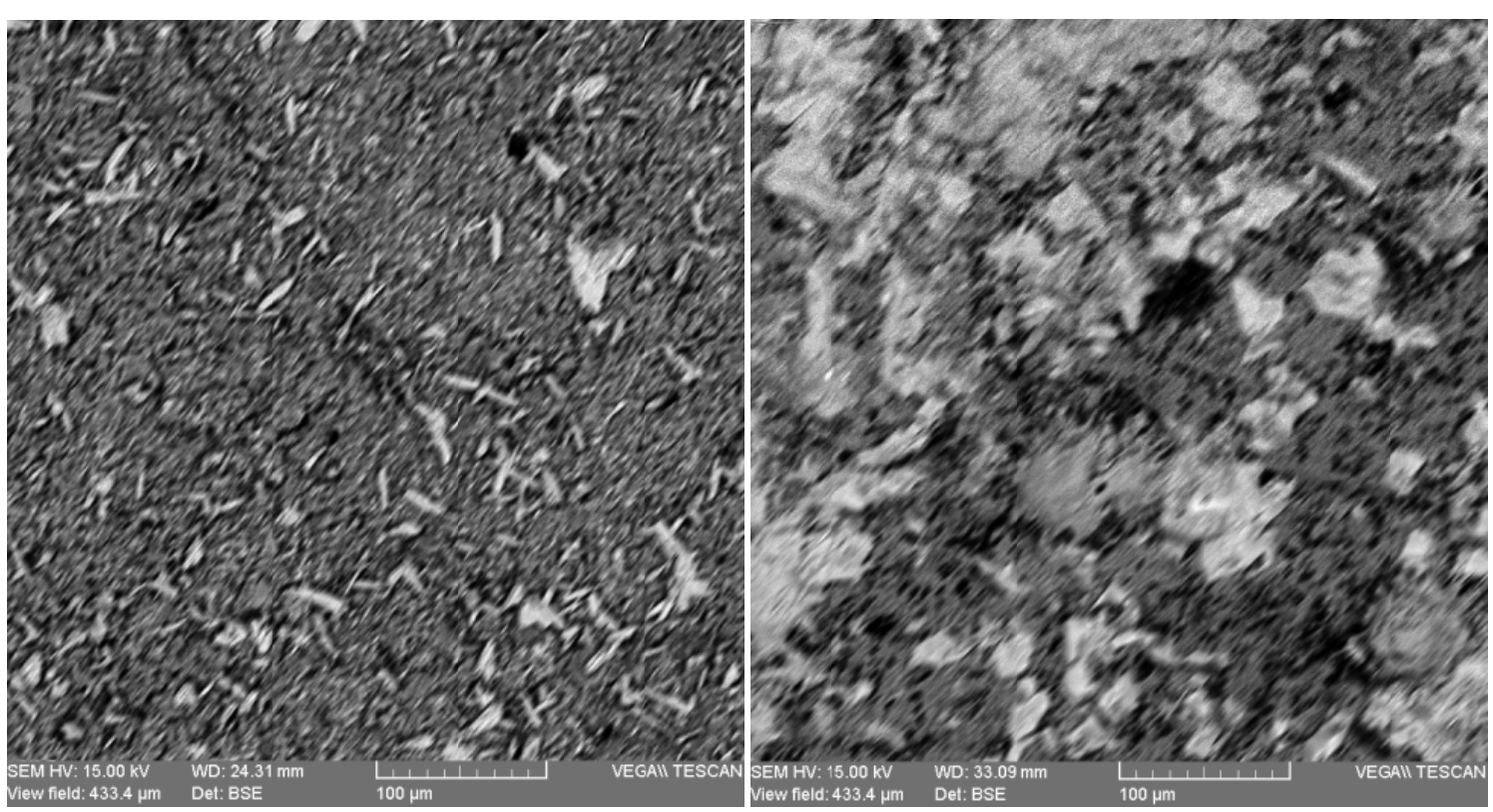

Fig. 1 a) section of activated vanadium pentoxide catalysts (increased $=500 x$ ) and $b$ ) section of spend vanadium pentoxide catalysts (increased $=500 x$ ).

activated vanadium pentoxide catalysts (increased $=$ $500 \mathrm{x})$ and b) section of spend vanadium pentoxide catalysts (increased $=500 \mathrm{x}$ ).

As observed Fig. 1a) section of activated vanadium pentoxide catalysts the porous surface is uniform, cleaned, and without waste while the b) section of spend vanadium pentoxide catalysts presents a porous surface covered by a residual layer and incrustations because sulfur, organic and inorganic residues du the process. Finally, the catalyst presents a pore size of 3 $\mathrm{nm}$ and a specific surface area of $200 \mathrm{~m}^{2} / \mathrm{s}$.

\subsection{Leaching Process}

\subsubsection{Pretreatment Influence}

Pretreatment of the catalyst was studied in the leaching process and the Table 3 shows the results. Leaching conditions were as leaching agent sulfuric acid (98\%) with concentration of $50 \mathrm{~g} / \mathrm{L}, 10 \mathrm{w} / \mathrm{w}$ solids percentage, environmental temperature, agitation speed was maintained $750 \mathrm{rpm}$ and 4 hours time leaching.

The results show the influence of the pretreatment, the increasing recovery of vanadium by using a calcination pretreatment for 3 hours at different fractions evaluated.

\subsubsection{Leaching Agents Influence}

Leaching agents and pretreatment influence were studied in the vanadium recovery and the Table 4 shows the results. Various leaching agents: sulfuric acid (98\%), hydrochloric acid (36\%) nitric acid (60\%) and sodium hydroxide (99\%) in $50 \mathrm{~g} / \mathrm{L}$ concentration were used in the process. Leaching conditions were 10 $\mathrm{w} / \mathrm{w}$ solids percentage, environmental temperature, agitation speed was maintained $750 \mathrm{rpm}$ and 4 hours time of leaching.

Table 4 shows that the recuperation percentage 
Table 3 Vanadium recovery from spent vanadium pentoxide catalysts at different particle size and pretreatment influence.

\begin{tabular}{lll}
\hline Mesh size & Pretreatment & Recovery \\
\hline$\# 150-\# 200$ & & $77.75 \%$ \\
$\# 150-\# 200$ & Calcination & $96.20 \%$ \\
$\# 200-\# 235$ & & $75.67 \%$ \\
$\# 200-\# 235$ & Calcination & $95.11 \%$ \\
$\# 325-\# 400$ & & $76.72 \%$ \\
$\# 325-\# 400$ & Calcination & $97.14 \%$ \\
\hline
\end{tabular}

Table 4 Vanadium recovery from spent vanadium pentoxide catalysts using different agents leaching.

\begin{tabular}{lll}
\hline Leaching agent & Pretreatment & Recovery \\
\hline Sulfuric acid (98\%) & & $75.67 \%$ \\
Sulfuric acid (98\%) & Calcination & $96.20 \%$ \\
Hydrochloric acid (36\%) & & $78.94 \%$ \\
Hydrochloric acid (36\%) & Calcination & $87.67 \%$ \\
Nitric acid (60\%) & & $74.95 \%$ \\
Nitric acid (60\%) & Calcination & $78.37 \%$ \\
Sodium hydroxide (99\%) & & $55.61 \%$ \\
Sodium hydroxide (99\%) & Calcination & $71.88 \%$ \\
\hline
\end{tabular}

Table 5 Vanadium recovery from spent vanadium pentoxide catalysts at different percentage of solids.

\begin{tabular}{lll}
\hline Percent solids & Concentration Vanadium $(\mathrm{g} / \mathrm{L})$ & Recovery \\
\hline $10 \mathrm{w} / \mathrm{w}$ & 3.61 & $96.20 \%$ \\
$15 \mathrm{w} / \mathrm{w}$ & 6.30 & $86.72 \%$ \\
$20 \mathrm{w} / \mathrm{w}$ & 8.70 & $82.88 \%$ \\
$25 \mathrm{w} / \mathrm{w}$ & 10.71 & $75.18 \%$ \\
$30 \mathrm{w} / \mathrm{w}$ & 10.93 & $72.36 \%$ \\
\hline
\end{tabular}

Table 6 Vanadium recovery from spent vanadium pentoxide catalysts at different percentage of solids and leaching agent concentration.

\begin{tabular}{llll}
\hline \multirow{2}{*}{ Concentration } & \multicolumn{3}{c}{ Recovery } \\
\cline { 2 - 4 } & $(10 \mathrm{w} / \mathrm{w})$ & $(20 \mathrm{w} / \mathrm{w})$ & $(25 \mathrm{w} / \mathrm{w})$ \\
\hline Sulfuric acid (98\%)-50 g/L & $96.20 \%$ & $82.88 \%$ & $75.18 \%$ \\
Sulfuric acid (98\%)-75 g/L & $97.41 \%$ & $94.41 \%$ & $88.77 \%$ \\
Sulfuric acid (98\%)-100 g/L & $97.34 \%$ & $96.14 \%$ & $91.42 \%$ \\
\hline
\end{tabular}

depends on the leaching agent and the pretreatement that was used. Sulfuric Acid (98\%) was the best leaching agent in the vanadium recovery if a calcination pre treatment is done, giving $96.2 \%$ of recovery.

\subsubsection{Percentage of Solids Influence}

Percentage of solids were evaluated in the vanadium recovery using as agent leaching sulphuric acid (98\%) in $50 \mathrm{~g} / \mathrm{L}$ concentration, calcined sample, environmental temperature, agitation speed was maintained $750 \mathrm{rpm}$ and 4 hours time of leaching. Table 5 shows the results.
Vanadium concentration increase as the percentage solids increase too, but the vanadium recovery decreased, that is why its important in order to obtain a higher concentration and a higher recovery by using the least amount of leaching agent.

\subsubsection{Leaching Agent Concentration Influence}

The leaching agent concentration was determinated at different percentage solids using as the leaching agent sulfuric acid, calcined sample, environmental temperature, agitation speed was maintained $750 \mathrm{rpm}$ and 4 hours time of leaching. The Table 6 shows the results of vanadium leaching at $10 \mathrm{w} / \mathrm{w}, 20 \mathrm{w} / \mathrm{w}$ and 25 


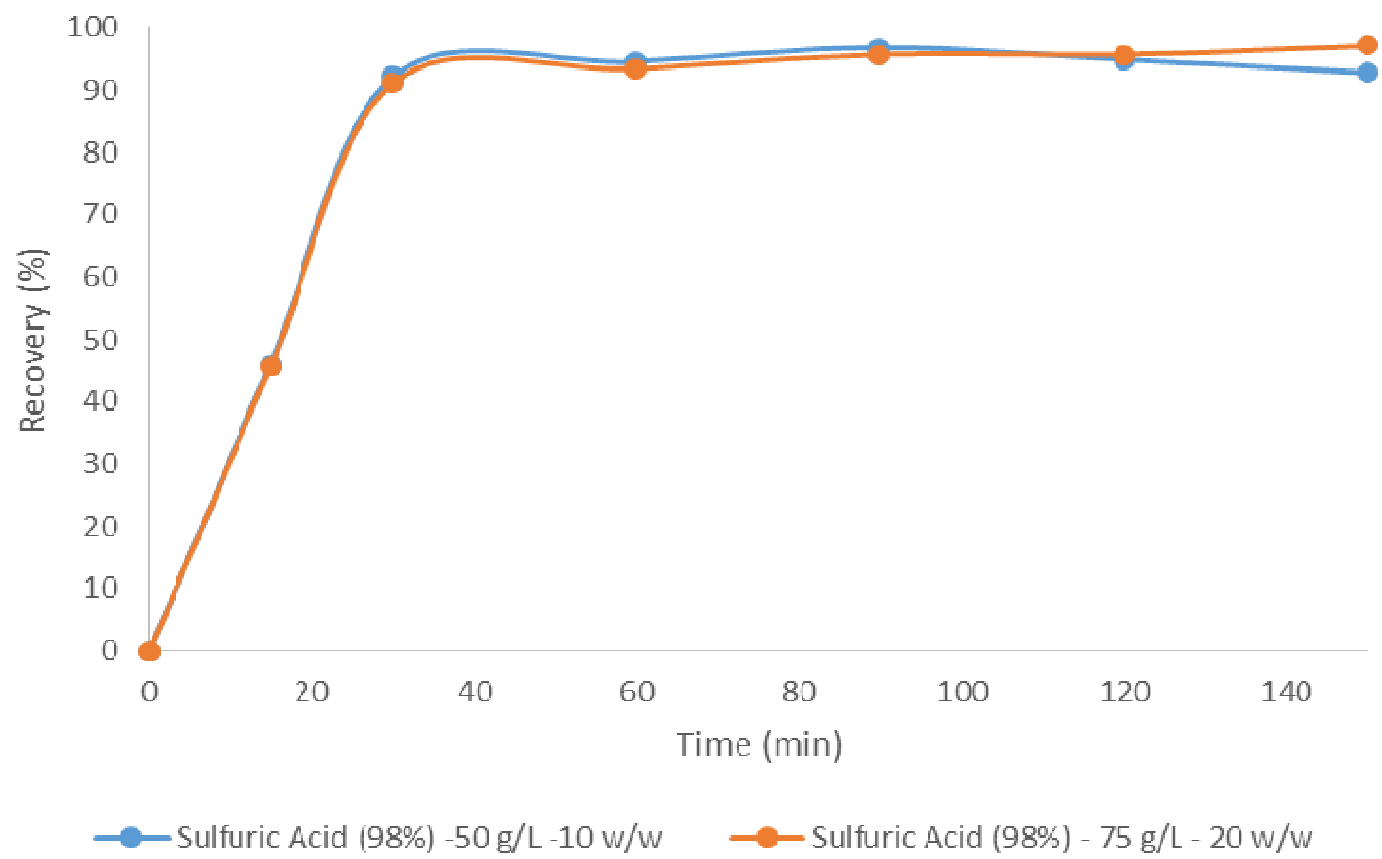

Fig. 2 Vanadium recovery (\%) during the time reaction $(\mathrm{min})$.

Table 7 Vanadium precipitation at different $\mathbf{p H}$.

\begin{tabular}{llll}
\hline Parameters & $\mathrm{pH}=3$ & $\mathrm{pH}=7$ & $\mathrm{pH}=12$ \\
\hline Volume sodium carbonate $(\mathrm{mL})$ & 12 & 36 & 64 \\
Vanadium recovery $(\%)$ & 16.69 & 92.2 & 44.15 \\
\hline
\end{tabular}

w/w solids percentage each one with sulfuric acid at 50 $\mathrm{g} / \mathrm{L}, 75 \mathrm{~g} / \mathrm{L}$ and $100 \mathrm{~g} / \mathrm{L}$.

Vanadium recovery increased as leaching agent concentration increased too, during all the process. Leaching at $10 \mathrm{w} / \mathrm{w}$ was similar, recovering around $97 \%$, leaching at $20 \mathrm{w} / \mathrm{w}$ the recovery increased from $82.88 \%$ to $96.14 \%$ and leaching at $25 \mathrm{w} / \mathrm{w}$ the recovery increased $75.18 \%$ to $91.42 \%$.

3.2.5 Leaching Time Influence-Kinetic of the Reaction

Kinetic of the reaction was studied at the best two better conditions of vanadium recovery, leaching with sulfuric acid at 50/L, $10 \mathrm{w} / \mathrm{w}$ solids percentage and the other leaching was realized with sulfuric acid at $75 \mathrm{~g} / \mathrm{L}$ and $20 \mathrm{w} / \mathrm{w}$ solids percentage. Results are presented in Fig. 2.

Vanadium recovery increased in the first thirty minutes, after that the recovery remained constant, for this reason thirty minutes was the optimum leaching time, during this time the recovery was high and the energy consumption by agitation was minimal. The best results were obtained by using sulfuric acid at 75 g/L, $20 \mathrm{w} / \mathrm{w}$ solids percentage and 30 minutes of leaching. The recovering vanadium rate was $94.41 \%$.

\subsection{Vanadium Precipitation}

\subsubsection{Effect of $\mathrm{pH}$ in Vanadium Precipitation}

Solution sodium carbonate $2 \mathrm{M}$ was added to the leaching solution to obtain a precipitate of sodium meta vanadate; the $\mathrm{pH}$ was changed in the process and it influence on the amount of sodium meta vanadate precipitation as Table 7 shows. The $\mathrm{pH}$ was controlled by adding different volume of solution sodium carbonate, three $\mathrm{pH}$ values are studied $=3,7,12$.

The $\mathrm{pH} 7$ was the optimal condition in the vanadium precipitation, because the ion meta vanadate was formed at this value. Later, the precipitate was calcined at $450{ }^{\circ} \mathrm{C}$ to obtain vanadium pentoxide. 


\section{Conclusions}

Vanadium recovery was increased when the catalyst is pretreated by calcining at $450{ }^{\circ} \mathrm{C}$ for 4 hours to remove coal and sulfur waste in the form of gas, as $\mathrm{CO}_{2}$ and SO.

The best results in vanadium leaching were obtained by using the following conditions: leaching agent sulfuric acid at $75 \mathrm{~g} / \mathrm{L}, 20 \mathrm{w} / \mathrm{w}$ percentage solids, environmental temperature, agitation speed was maintained $750 \mathrm{rpm}$ and 30 minutes leaching. The Recovering vanadium rate was $94.41 \%$.

Finally, in the precipitation stage $92.2 \%$ of sodium meta vanadate, for that a $\mathrm{pH} 7$ was required.

\section{References}

[1] Gracía, J., Lozano, J., and Mulero, M. 2001. "Leaching of Vanadium Acid Manufacture Spent Catalysts.” Revista Metalurgia, 18-23.
[2] Khorfan, S., Wahoud, A., and Reda Y. 2002. "Recovery of Vanadium Pentoxide from Spent Catalyst Used in the Manufacture of Sulphuric Acid.” Periodica Polyrtechnica Ser. Chem. Eng. 45: 131-7.

[3] Torres, L., Kharisov, B., and Elizondo, N. 2001. "Recuperación de V y Mo de Catalizadores Gastados de la Industria Petroquímica.” Ciencia UANL 2: 198-204.

[4] Torres, E., Guevara, A., and Ibujés, P. 2009. "Recuperación de Niquel y Vanadio de la Combustión de Fueloil, Mediante Lixiviación con Ácido Sulfúrico y Carbonato de Sodio.” Revista Politécnica 30: 29-36.

[5] Garcia, C., Rosales, R., Feijoo, B., Hernández, J., González, J., and Carruto, G. 2013. "Evaluación de la Recuperación de Vanadio y Níquel por Lixiviación Ácida de las Cenizas Volantes del Aceite Combustible.” Revista Tecnocientífica URU 5: 39-48.

[6] Campos, G., Rivas, E., Sánchez, L., Cáceres, A., Bravo, B., Chávez, G., Ysambertt, F., Marquez, N., and Acevedo, S. 2012. "Estudio de Recuperación de Vanadio y Níquel en un Crudo Pesado y en su Fracción de Asfaltenos y Maltenos por ICP-OES.” Revista Ciencia 2: 52-9.

[7] Sigma-Aldrich. 2015. "Vanadium Pentoxide." catalog. 